\title{
Construction of Risk Identification and Assessment Index System of Logistics Park Construction Project
}

\author{
$\mathrm{He} \mathrm{Qi}^{1, \mathrm{a}}$ \\ ${ }^{1}$ Economic and Management Department, Tianjin University of Science \& Technology, Tianjin \\ 300222, China \\ a316385159@qq.com
}

Keywords: Logistics Park; Risk Assessment; Risk Management

Abstract: Logistics park construction is a is a large investment. Due to its long payback period, it is a high risk project. It has lots of possible impact factors. The construction errors will cause large range, long time and irreparable losses to the enterprise and the society. Therefore, it is of great practical significance to change the traditional risk management model of the construction project management, and to carry out the research on the risk management of logistics park construction project. The scientific method, the logistics park construction project risk identification, and assessment and control are discussed in this paper. The research results enrich and improve the logistics park construction project risk management theory to guide the scientific management of the logistics park construction project, this paper also has a certain theoretical guidance and practical reference value.

\section{Introduction}

Promulgated by the State Council on the 《Adjustment and Revitalization Plan of the Logistics Industry $\rangle$, the logistics park included in promoting the development of modern logistics, "nine key projects" to give a high degree of attention. As an important infrastructure for the development of the logistics industry, logistics parks are treated as the implementation of the revitalization plan in many provinces and cities. 《Opinions of the general office of the State Council on promoting policies and measures for the healthy development of the logistics industry $》$ says: the people's governments at all levels to increase the support of logistics infrastructure investment, to meet the conditions of the key logistics enterprises of transportation, warehousing, distribution, information infrastructure and logistics park's infrastructure construction give necessary financial support ${ }^{[1]}$. The research discovered that many road freight hub (Logistics Park) in our country has the specific problems of function dissimilation, wasting of resources, service low and so on. There are great risks in the construction of logistics parks. Through the analysis of the uncertain factors of the construction project of Logistics Park, identify the key risk factors in the construction of the logistics park, can help managers to seize the focus of the work, the main focus on major risks. Through the research on the risk attributes of logistics park construction project, it is beneficial to avoid and control the risk from different levels, and improve the accuracy and practicality of the logistics park construction project.

\section{The risk of logistics park construction project overview}

The meaning of the risk of logistics park construction project. Risk refers to the uncertainty of the actual results in a given environment, in a given period of time and the actual results with respect to the expected expectations. The risk of logistics park construction project is the construction and management of the project in the area of logistics park, the potential possibilities of the logistics park construction project can not reach the expected goal (time limit, cost, quality and social logistics costs, ease traffic pressure, promote environmental protection and sustainable development, etc) by the existence of various uncertain factors. 


\section{The cause of the risk of logistics park construction project.}

Uncertainty of external conditions. Logistics park construction project takes the project as the core. The project stakeholders from the design, supervision contractors, suppliers, owners and other stakeholders constitute a project supply chain. In the supply chain, each participating party has a lot of uncertainty. At the same time, the uncertainty of natural environment and the construction of future changes such as geological, hydrological conditions of uncertainty and land supply, change of policies and regulations, urban planning adjustments may bring adverse effects to the project.

The limitation of subjective cognition. The limitations of the subjective cognition refer to that the project decision-making and management personnel to the construction of logistics park, which are involved in all aspects of knowledge and technology, have limitations in understanding and master degree. They can not be completely accurately predict the change trend of market, technology and other aspects, which will case technology leading or lagging, scale unsuitable and inaccurate positioning and so on. Thus, there are risks in the construction of logistics parks ${ }^{[2]}$.

Uncertainty of market. The derived characteristics of logistics park determines that market demand is the condition for Logistics Park's survival. But market is changing all the time. The uncertainty of market mainly expressed as follows: the uncertainty of the relationship between supply and demand, the uncertainty of the market price, the uncertainty of market innovation ability etc.. The uncertainty of the relationship between supply and demand is the most crucial.

\section{The basis of risk identification for the construction project of Logistics Park}

Field investigation in the early stage of the project. At the early stage of the project field investigation includes: file design, Hydro geological and meteorological conditions, topographic and geomorphic features, hydrogeological conditions, meteorological conditions, topography, natural and secondary disasters ${ }^{[3]}$. Peripheral matching conditions, traffic and communication conditions, the local public security and the price level, Local design and construction level, local policies, laws and regulations etc..

The premise of the construction of the project. Project proposal, feasibility study report, design or other documentation of logistics park construction are generally based on certain assumptions. When the risk is identify, the premise of the project, should also be used as a reference basis. For example, the construction scale of logistics park is based on the future demand.

Project overview and related management planning. The project risk identification is based on the project general situation and the project management plan, including project objectives, tasks, scope, resource planning, schedule planning, cost planning, quality planning and procurement plans and stakeholder's expectation and so on.

The historical data of the project management formed. The historical data of the project is one of the important bases for the risk identification, such as record of past construction project, project summary, project acceptance data, project quality and safety incident handling documents, as well as project changes and construction claims data, etc.. These data detailing the project quality, safety accidents and Construction claims processing, is very helpful in risk identifying of current logistics park construction project.

\section{Construction of risk assessment index system of logistics park construction project}

The construction principle of risk assessment index system. The risk assessment of logistics park construction project is not only to assess the possibility of the project risk, but also to trace the causes of accidents and analysis the consequences of the accident and its influence degree. Meanwhile, the risk assessment can use the quantitative data (rather than qualitative analysis), to compute a number of economic and technical indicators to reflect the whole logistics park construction project system's security, reliability, economy and so on. In addition, the systematic and comprehensive risk assessment and analysis of the logistics park construction project can improve the 
government, owners, design units, contractors, and logistics park platform operators of risk management awareness and risk management capabilities.

Construction of index system of risk assessment. Compared with the general construction project, the logistics park construction project has the following characteristics: large scale of construction, huge investment, high technical requirements, long construction period, public welfare projects and enterprises coexist and diverse ways of investment and financing, system complex, high quality requirements of the project, complex all the technology, technical risk large ${ }^{[4]}$. These characteristics determine the logistics park in the construction process, containing a lot of risks. Therefore, to explore a scientific, reasonable, strong operability, suitable to the demands of the logistics park construction project risk management risk assessment index system is very important.

Technical risk. The definition of Technical risk is that during the logistics park construction and the operation in planning, insufficient or technical analysis and decision-making uncertainty and other reasons may bring the risk of the logistics demand analysis, the function design and other aspects, so as to bring harm or potential accident loss to the construction projects of logistics park investment management. Such as the wrong construction technology and construction scheme in the construction process because of not considering the influence of geological conditions; logistics facilities and layout planning, planning too far ahead or behind. The logistics park construction project risk factors are mainly caused by technical and scientific research: completeness, reasonable location suitability, scale, reasonable layout, functional design, advanced technology, design risk, rationality of the design process.

Economic and Financial Risk. Economic and financial risk is due to the logistics park construction projects, unreasonable financial structure, poor cost control change and other relevant economic factors. financial economic risks directly affect the amount of investment and whether the construction projects are promoted smoothly. The main factors that affect the financial economic risks are: financial risk (interest rate and exchange rate changes), inflation, domestic macroeconomic and regional economic sources of funding for land properties, tax policy ${ }^{[5]}$.

Market risk. Market risk refers to that when the logistics park project is put into operation, because of the uncertainty factors like changes in market demand for logistics, the application of new technology, industrial structure adjustment, regional or city, the service level and the scale of the project and the market demand, marketing and logistics park management mechanism to influent the risk of production, which brings low rate logistics park occupancy , a large number of idle equipment, the actual income is lower than expected, thereby affecting the survival and development of the logistics park. Return logistics park depends directly on the price of logistics service and the logistics service supply, and logistics demand, logistics market competition and business park can provide the level of service marketing ability. Thus the effect of market risk factors of logistics park are: logistics demand outlook, with the degree of competition in the industry, product market positioning service, Service ability and level, marketing planning ability, logistics enterprise's level of understanding, regional industrial structure adjustment.

Natural and environmental risks. Natural and environmental risk is the risk that because of the natural environment and the external environment changes have a bad influence on the construction of logistics park, and logistics park construction on the surrounding environment to produce adverse effects. In the project implementation during the nature of climate change, bad engineering geological and hydrological conditions of logistics park project construction, and the construction of logistics park on the surrounding environment will have an impact. These factors which have an impact on environmental are: Engineering Geology and hydrological geology, natural disasters, the convergence of the network supporting the project, the operation of the park on the surrounding environment influence.

\section{Conclusions}

Through the analysis of the index of logistics park construction project risk evaluation index system, we can find that the logistics park construction project risk not only has the general construction project characteristics, the risk index also has its own unique. In the logistics park is different from the 
general construction projects mainly focus on project products (services) wood the use value and economic value, and has the public welfare characteristics, making it a government, change the nature of the land and other risks. These risks show logistics park construction project, stream park construction project risk management in object, on the basis of the theory of risk management of construction project, characteristics combined with the construction of logistics park project risk, according to the inherent law of risk, design appropriate risk analysis, evaluation model, and then puts forward the scientific and effective risk control. Coping strategies and methods.

\section{References}

[1] Guowen Ren, Yingjie Huang. The Layout Optimization Model and Algorithm of Logistics Park Potential,[M].Proceedings of the 22nd International Conference on Industrial Engineering and Engineering Management 2015,Atlantis Press, Part II, pp 479-488

[2] Fuhua Wang, Zhixue Liu,Inspiration and Reference from Japanese Logistics Park's Construction and Development[J].Asian Social Science, 2009, Vol.4 (6):74-77

[3] Lijuan Huang.Modeling and Planning on Urban Logistics Park Location Selection Based on the Artificial Neural Network[J]. Journal of Computers,2012, Vol.7 (3), pp.792-797

[4] M. Šulgan,Logistics park development in Slovak Republic[J].Transport,2006, Vol.21 (3), pp.197

[5] Wang Yuzhou, He Yinjun, Chen Zeyun. Study on Risk Evaluation for Logistics Park Construction Project Based on Fuzzy Comprehensive Evaluation Model[A]. Shanghai Normal University, 2012:4. 